Check for updates

Cite this: Chem. Sci., 2019, 10, 10053

๑ All publication charges for this article have been paid for by the Royal Society of Chemistry

Received 22nd July 2019

Accepted 2nd September 2019

DOI: $10.1039 / c 9 s c 03594 j$

rsc.li/chemical-science

\section{Charge-driven tripod somersault on DNA for ratiometric fluorescence imaging of small molecules in the nucleus $\uparrow$}

\author{
Kang-Nan Wang, (D) Qian Cao, ${ }^{*}$ Liu-Yi Liu, Zi-Jian Zhao, Wenting Liu, Dan-Jie Zhou,
} Cai-Ping Tan, (I) Wei Xia, (D) Liang-Nian Ji and Zong-Wan Mao (iD *

\begin{abstract}
Although fluorescence tracing of small bioactive molecules in living cells has been extensively studied, it is still a challenging task to detect their variations in the nucleus mainly due to the impermeable nuclear membrane and nucleic acid interference. Herein, we take advantage of the nucleic acid enriched environment in the nucleus to establish a strategy, named "charge-driven tripod somersault on DNA", for ratiometric fluorescence imaging of small bioactive molecules in the nucleus. Taking $\mathrm{SO}_{2}$ derivatives as a typical target analyte, a tripodal probe has been constructed by conjugating two DNA binding groups containing a $\mathrm{SO}_{2}$ derivative reaction site. Mechanism studies demonstrate that upon encountering and reacting with $\mathrm{SO}_{3}{ }^{2-} / \mathrm{HSO}_{3}{ }^{-}$, a charge variation occurs at the responsive arm of the tripodal probe, triggering a tripod somersault on DNA, resulting in the conformational rearrangement of the DNA binding modes with DNA-modulated fluorescence change, which allows the second emission feature to emerge. In this strategy, probe-DNA binding is not influenced by RNA or non-specific protein association, thus making it ideal for tracing nucleus-localized analytes. The application of this strategy has realized both in vitro and in vivo ratiometric fluorescence imaging of the variations of endogenous $\mathrm{SO}_{2}$ derivatives in the nucleus for the first time, with high specificity and selectivity. Also, in theory, this strategy opens up a new avenue for the design of fluorescence probes for the nucleus-localized biological analytes.
\end{abstract}

\section{Introduction}

The nucleus is the most important organelle in eukaryotic cells and is generally recognized as the regulatory centre of cell activity, heredity, and metabolism. ${ }^{1,2}$ The occurrence and development of many fundamental diseases are usually accompanied by abnormal nuclear behaviour. ${ }^{3-5}$ It has been found that many endogenous bioactive molecules at an imbalanced level can interfere with genetic materials within the nucleus and cause nuclear dysfunction, although at physiological concentrations they also act as messengers featuring a cytoprotective effect and maintaining cellular homeostasis. For example, excess $\mathrm{ClO}^{-}$and $\mathrm{H}_{2} \mathrm{O}_{2}$ can cause the accumulation of ROS-mediated oxidative damage to the nuclear genetic materials, resulting in aging, Alzheimer's disease and cancer; ${ }^{6,7}$ nuclear metal ions such as $\mathrm{Zn}^{2+}, \mathrm{Cr}^{3+}$, and $\mathrm{Al}^{3+}$ can form a hinge

MOE Key Laboratory of Bioinorganic and Synthetic Chemistry, School of Chemistry, Sun Yat-sen University, Guangzhou, 510275, P. R. China. E-mail: caoqian3@mail. sysu.edu.cn; cesmzw@mail.sysu.edu.cn; Fax: +86 2084112245

$\dagger$ Electronic supplementary information (ESI) available: Synthesis and characterization; DNA titration experiments, cytotoxicity of probes, and so on. CCDC 1893794. For ESI and crystallographic data in CIF or other electronic format see DOI: $10.1039 / \mathrm{c} 9 \mathrm{sc} 03594 \mathrm{j}$ with nucleic acids and hinder gene expression; ${ }^{8-10}$ inhalation of $\mathrm{SO}_{2}$ results in abnormal nuclear behaviour ${ }^{11}$ and DNA damage in multiple organs, ${ }^{12,13}$ contributing to the development and progression of ischemic stroke in the brain. Therefore, directly and specifically tracking the flux of these small bioactive molecules in the nucleus offers a potentially reliable indicator for the progression of disease states.

As is known to all, fluorescence combined with confocal microscopy is an indispensable tool for visualizing biological events with high sensitivity and high-contrast spatiotemporal resolution. ${ }^{14,15}$ Compared with the conventional fluorescence "turn-on" strategy, ${ }^{16}$ self-referencing ratiometric fluorescence offers greatly improved sensitivity and reliability, relying on the intensity changes of two or more emission features, thus eliminating a variety of interference factors, e.g. fluorophore concentrations, instrumental parameters, cellular auto-fluorescence, etc. ${ }^{17-21}$ Currently, ratiometric fluorescence sensing is mainly achieved by the following strategies: (1) internal charge transfer (ICT) for e.g. $\mathrm{H}_{2} \mathrm{~S}$ and $\mathrm{H}_{2} \mathrm{O}_{2}$ sensing in living cells;; ${ }^{22,23}$ (2) Förster resonance energy transfer (FRET) for quantifying e.g. phosphodiesterase activity; ${ }^{24}$ (3) excited state intramolecular proton transfer (ESIPT) for probing biologically relevant cations and anions $\left(\mathrm{Zn}^{2+}, \mathrm{F}^{-}, \mathrm{CH}_{3} \mathrm{CO}_{2}{ }^{-}, \mathrm{H}_{2} \mathrm{PO}_{4}^{-}\right.$, etc. $) ;{ }^{25,26}$ (4) throughbond energy transfer (TBET) for measuring e.g. in vivo 
intracellular $\mathrm{pH}$ values; ${ }^{27,28}$ (5) monomer-excimer based ratiometric sensing driven by analyte-induced changes in the separation of excimers, etc. ${ }^{29,30}$ However, utilizing these strategies to construct probes requires complex design and synthesis as well as the accurate matching of energy levels, which makes the difficulty and workload relatively great. Moreover, although the ratiometric fluorescence sensing of these bioactive molecules in the whole cell, cytoplasm, and mitochondria has been widely explored, ${ }^{19,31,32}$ it is still a challenging task to trace their flux in the nucleus. Indeed, the rare examples only include nuclearlocalized probes NucPE1, SNAP-PG and a highly sensitive probe NP1 responding to the changes of nuclear $\mathrm{H}_{2} \mathrm{O}_{2}$ fluxes, ${ }^{33-35}$ a photo-stable $\mathrm{pH}$ probe $\mathrm{NaOCy}$ and a ratiometric fluorescence $\mathrm{pH}$ probe hoeFL for selectively staining nuclei in living cells; ${ }^{36,37}$ a sulfur-containing fluorogenic probe JG45 for selectively detecting nuclear methylmercury $\left(\mathrm{MeHg}^{2+}\right) \cdot{ }^{38}$ The difficulty in visualizing the flux of bioactive molecules in the nucleus is mainly due to the impermeable nuclear membrane and the interference of the complex nucleic acid environment with the fluorescence of probes. ${ }^{39,40}$

On the other hand, numerous DNA and RNA binding agents have been reported, exhibiting nucleic acid induced fluorescence turn-on properties for selectively staining the DNA-rich nucleus and RNA-rich nucleolus. ${ }^{41-45}$ This provides an idea that conjugating two DNA binding groups with different DNA affinities in one probe may exhibit two different emission features based on the DNA binding modes and the DNA-modulated fluorescence. Simultaneously, utilizing DNA binding agents to construct fluorescent probes can also resolve the nuclear-targeting problem. ${ }^{46}$ With these criteria in mind, we establish a ratiometric fluorescence imaging strategy, named "charge-driven tripod somersault on DNA" by taking advantage of the nucleic acid enriched environment in the nucleus and the conjugation of two DNA binding groups. Herein, $\mathrm{SO}_{2}$ derivatives (sulfite $\mathrm{SO}_{3}{ }^{2-}$ and bisulfite $\mathrm{HSO}_{3}{ }^{-}$) are taken as a typical target analyte to clarify the mechanism of action of this novel strategy. Generally, sulphite and bisulphite in neutral fluid and plasma exist in equilibrium $(3: 1$, $\mathrm{M} / \mathrm{M}$ ), and the concentration of total serum sulphite is $0-9.85 \mu \mathrm{M}$ in healthy donors. ${ }^{47,48}$ Measurements of nuclear $\mathrm{SO}_{2}$ derivatives are undoubtedly valuable, because exposure to $\mathrm{HSO}_{3}{ }^{-}$can cause abnormal nuclear behavior including increased incidence rates of chromosomal aberrations, sister chromatid exchanges and micronuclei. $\mathrm{SO}_{2}$ derivatives can also induce DNA damage in multiple organs (the brain, lungs, liver, spleen, kidneys, intestines, and testicles) in vivo in a dose-dependent manner. ${ }^{11-13}$ However, detecting analytes in the nucleus is always very challenging due to the impermeable nuclear membrane and the interference of nucleic acids with the fluorescent probes. ${ }^{49-51}$ So far, reports on the variations of $\mathrm{SO}_{2}$ derivatives in the nucleus are still lacking although the cellular and mitochondrial $\mathrm{SO}_{2}$ derivatives have been widely explored..$^{52-57}$

As shown in Scheme 1, a tripodal probe named [PAST $]^{+}((E)-$ 2-(4-(bis(4-(pyridin-4-yl)phenyl)amino)styryl)-3-methylbenzo[d] thiazol-3-ium iodide) has been designed by conjugating a dipyridyltriphenylamine fluorophore and a benzothiazole salt, both of which are DNA binding agents, through an ethylene group, which is the reaction site with $\mathrm{SO}_{2}$ derivatives. Before
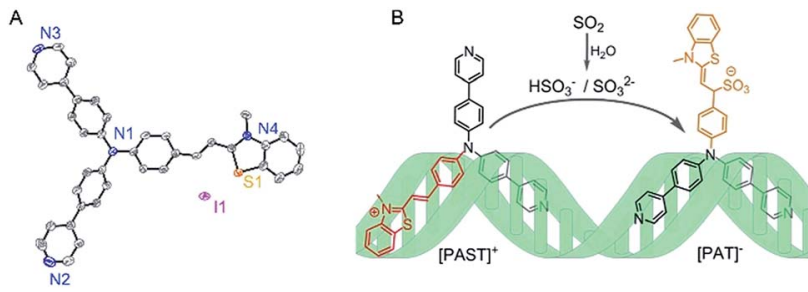

Scheme 1 (A) X-Ray crystal structure of [PAST] ${ }^{+}$(CCDC number: $1893794 \dagger$ ), in which the hydrogen atoms are omitted for clarity and the counter ion is $\mathrm{I}^{-}$; (B) schematic illustration of the strategy named "charge-driven tripod somersault on DNA" for ratiometric fluorescence imaging of small bioactive molecules in the nucleus: the tripodal probe $[\mathrm{PAST}]^{+}$is constructed by connecting two DNA binding moieties with an ethylene group; once the DNA-[PAST] ${ }^{+}$reacts with the negatively charged target analyte, the newly formed tripod [PAT] ${ }^{-}$ gradually dissociates from the DNA system, freely rotates, and ultimately seizes back the DNA with different binding modes, thus resulting in the disappearance of the first emission feature from DNA[PAST $^{+}$and the emergence of the second emission feature from DNA-[PAT $]^{-}$

encountering the target analyte, the tripod binds to DNA via the positively charged benzothiazole moiety and one uncharged arm of dipyridyltriphenylamine, thus giving the first emission feature; after reacting with the negatively charged target analyte, the newly formed tripod [PAT] ${ }^{-}((Z)-1-(4-($ bis(4-(pyridin-4-yl)phenyl) amino)phenyl)-2-(3-methylbenzo[d]thiazol-2(3H)-ylidene)ethanesulfonate) gradually dissociates from the DNA system due to the Coulomb repulsion between the negatively charged benzothiazole- $\mathrm{SO}_{2}$ group and DNA backbone, and then becomes free to rotate in the solvent and ultimately seize back the DNA system via the two inherent neutral arms of dipyridyltriphenylamine whereas the benzothiazole- $\mathrm{SO}_{2}$ group stretches out. Such a change in the DNA binding mode results in the disappearance of the first emission feature (red emission) and the formation of the second emission feature (yellow emission), thus giving the ratiometric fluorescence spectra. Accordingly, we name this strategy the "charge-driven tripod somersault on DNA". By using this, both in vitro and in vivo ratiometric fluorescence imaging of the variations of endogenous $\mathrm{SO}_{2}$ derivatives in the nucleus have been realized for the first time.

\section{Results and discussion}

\section{Synthesis and characterization of $[\mathrm{PAST}]^{+}$and $[\mathrm{PAT}]^{-}$}

The probe [PAST $]^{+}$was synthesized and isolated (Scheme S1, $\mathrm{ESI}+$ ) and fully characterized by HRMS, ${ }^{1} \mathrm{H}$ NMR, ${ }^{13} \mathrm{C}$ NMR, elemental analysis and X-ray crystallography (Scheme 1A, Fig. S1-S3 and Tables S1-S3, ESI $\dagger$ ). ${ }^{1} \mathrm{H}$ NMR investigation (DMSO- $d_{6} / \mathrm{D}_{2} \mathrm{O}, 4: 1$ ) shows that upon $\mathrm{HSO}_{3}{ }^{-}$addition, the resonance signals corresponding to the alkene protons of [PAST $]^{+}$disappear, (Fig. S4, ESI $\dagger$ ), indicating the nucleophilic addition of $\mathrm{HSO}_{3}{ }^{-}$to the double bond of the benzothiazole ethylene salt, resulting in the formation of $[\mathbf{P A T}]^{-}$, as briefly depicted in Scheme 1. Pure [PAT] ${ }^{-}$was also isolated for structural characterization by HRMS, ${ }^{1} \mathrm{H}$ NMR, ${ }^{13} \mathrm{C}$ NMR, and elemental analysis (Scheme S1 and Fig. S5-S7, ESI $\dagger$ ). 
Furthermore, the reaction between $[\mathbf{P A S T}]^{+}$and $\mathrm{HSO}_{3}{ }^{-}$to produce $[\mathbf{P A T}]^{-}$was tracked by HPLC, and the HPLC retention time compared with those of independently synthesized [PAST] ${ }^{+}$ $(4.21 \mathrm{~min})$ and $[\mathbf{P A T}]^{-}$(33.89 $\left.\mathrm{min}\right)$ further demonstrated the purity of both compounds (Fig. S8, ESI $\dagger$ ). The photophysical properties of $[\mathbf{P A S T}]^{+}$and $[\mathbf{P A T}]^{-}$including the quantum yields, extinction coefficients, and fluorescence lifetimes were recorded in various solvents (Fig. S9 and Table S4, ESI $\dagger$ ).

\section{Spectral response of $[\mathrm{PAST}]^{+}$toward $\mathrm{SO}_{2}$ derivatives in PBS or DNA enrichment buffer}

Before spectral response studies, the interference of [PAST] ${ }^{+}$ self-aggregation was first excluded. Crystal data show that $\pi-\pi$ stacking forces (distance: $4.163 \AA$ and $4.384 \AA$ ) and intermolecular hydrogen bonding interactions (bond length: $2.501 \AA$ and bond angle $157.991^{\circ}$ ) between adjacent [PAST] ${ }^{+}$molecules contribute to the self-aggregation of [PAST $]^{+}$(Fig. S10, ESI $\dagger$ ). The concentration-dependent absorption/fluorescence spectra show that the linear relationship is only observed in the concentration range of $0.1-120 \mu \mathrm{M}$ (Fig. S11, ESI $\dagger$ ). This indicates that [PAST $^{+}$only undergoes self-aggregation at high concentrations
$(>120 \mu \mathrm{M})$, thus excluding the influence of self-aggregation on the reliability of the fluorescence response in the following imaging experiments using $20 \mu \mathrm{M}$ [PAST $]^{+}$.

The response of [PAST] $]^{+}$to $\mathrm{HSO}_{3}{ }^{-}$was initially investigated in PBS $(\mathrm{pH}=7.4)$. With increasing concentrations of $\mathrm{HSO}_{3}{ }^{-}(0-$ $10 \mu \mathrm{M})$, the absorption of [PAST] $]^{+}$at $515 \mathrm{~nm}$ gradually decreases (Fig. 1A) and the colorimetric changes $\left(\mathrm{A}_{515} / \mathrm{A}_{345}\right)$ show a good linear relationship (Fig. S12A, ESI $\dagger$ ). Upon $515 \mathrm{~nm}$ excitation, [PAST] $^{+}$exhibits a near-infrared emission centered at $735 \mathrm{~nm}$, which is gradually quenched upon $\mathrm{HSO}_{3}{ }^{-}$titration (Fig. 1B). The quick fluorescence response $(<1 \mathrm{~min})$ of $[\mathbf{P A S T}]^{+}$to $\mathrm{SO}_{2}$ derivatives demonstrates its potential for real-time detection (Fig. S12B, ESI $\dagger$ ). And the limit of detection (LOD) value of [PAST] $]^{+}$for $\mathrm{SO}_{2}$ derivatives is determined to be $25.4 \mathrm{nM}$ in a PBS environment (Fig. S13A, ESI $\dagger$ ). The mechanism of the absorbance/emission change of [PAST] ${ }^{+}$towards $\mathrm{SO}_{2}$ derivatives is explained by the HOMO and LUMO distributions of [PAST $]^{+}$and

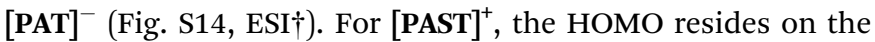
whole conjugated structure while the LUMO primarily resides on the benzothiazole ligand. However, the 1,4-addition of $\mathrm{HSO}_{3}{ }^{-}$to the $\mathrm{C}=\mathrm{C}$ bond breaks the conjugated structure and generates $[\mathbf{P A T}]^{-}$, in which the HOMO resides on the
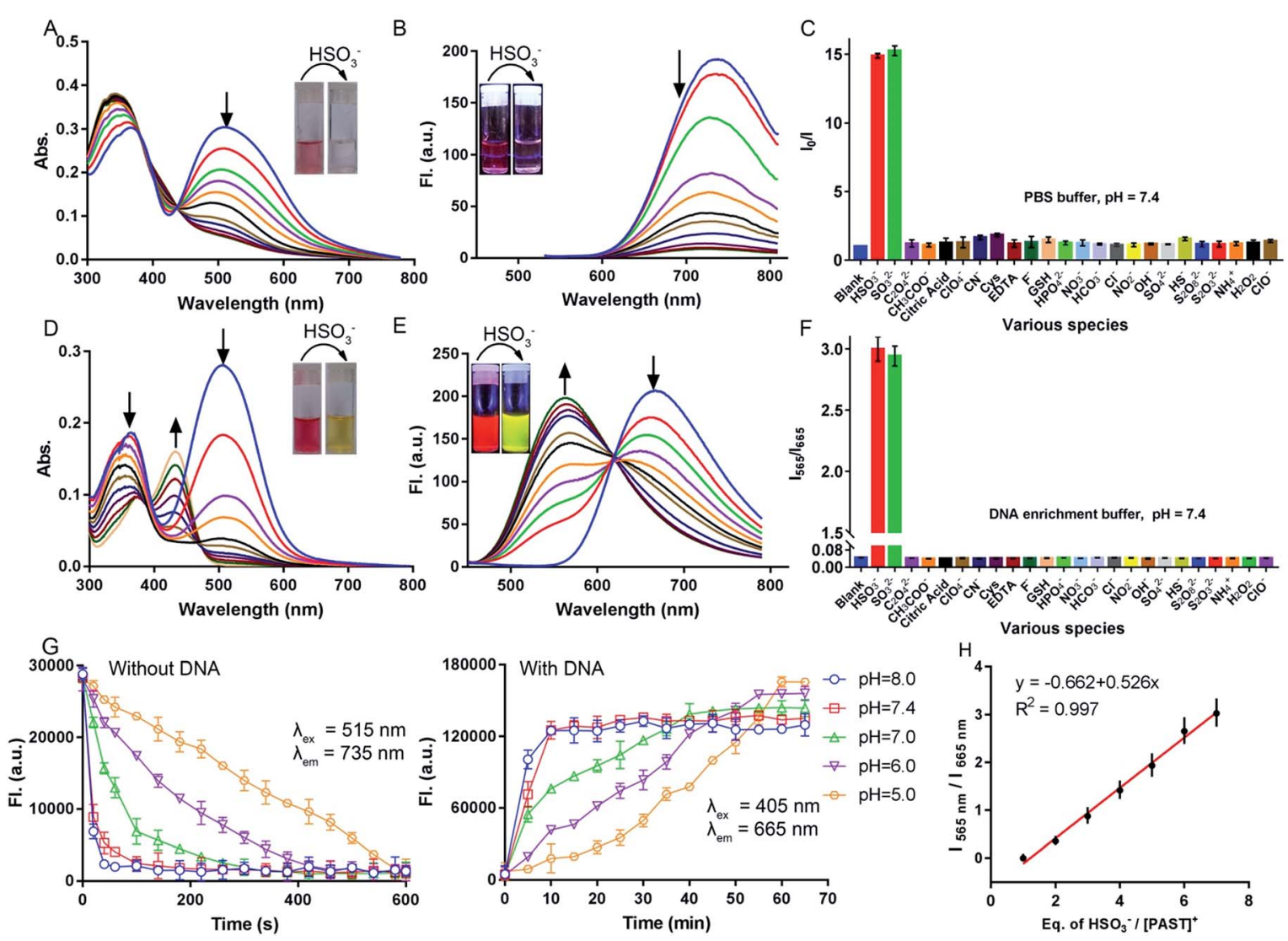

Fig. 1 UV-Vis absorption and emission spectra of [PAST] $]^{+}(10 \mu \mathrm{M})$ upon $\mathrm{HSO}_{3}{ }^{-}$titration in (A and $\left.\mathrm{B}\right) \mathrm{PBS}$ solution and (D and E) DNA enrichment buffer solution (dsDNA $6.0 \mu \mathrm{M}$ ), respectively, (the $\mathrm{HSO}_{3}{ }^{-}$concentration for ( $\mathrm{A}$ and $\mathrm{B}$ ) is $0-10 \mu \mathrm{M}$ and for ( $\mathrm{D}$ and $\mathrm{E}$ ) is $0-100 \mu \mathrm{M}$ ). Inset: photograph showing the corresponding absorption and fluorescence (under a $365 \mathrm{~nm}$ UV lamp) response seen by the naked eye; (C and F) changes in the fluorescence intensity of [PAST] ${ }^{+}(10.0 \mu \mathrm{M})$ after incubation with various biologically relevant analytes $(2 \mathrm{mM}, 30 \mathrm{~min})$ in PBS $\left(/ / I_{0}, \lambda_{\text {ex }}=515 \mathrm{~nm}\right)$ and DNA enrichment buffer solution $\left(I_{565} \mathrm{~nm} / I_{665 \mathrm{~nm}}, \lambda_{\text {ex }}=405 \mathrm{~nm}\right)$; (G) fluorescence response rate of [PAST] ${ }^{+}(10.0 \mu M)$ to HSO ${ }_{3}^{-}$in aqueous solution with or without dsDNA $(6.0 \mu \mathrm{M})$ at various $\mathrm{pH}$ values $(5.0-8.0)$. (H) Linear relationship between the changes of the $I_{565} \mathrm{~nm} / I_{665} \mathrm{~nm}$ emission ratio $\left(\lambda_{\mathrm{ex}}=405 \mathrm{~nm}\right.$ ) and equivalents of $\mathrm{HSO}_{3}{ }^{-} /[\mathrm{PAST}]^{+}$, (the $[\mathrm{PAST}]^{+}$concentration: $10 \mu \mathrm{M}$, the data were collected from (E)). 
benzothiazole ligand while the LUMO is primarily delocalized on the dipyridyltriphenylamine fluorophore. Accordingly the energy gaps between the HOMO and LUMO are greatly influenced and calculated to be $2.26 \mathrm{eV}$ and $2.56 \mathrm{eV}$ for [PAST] ${ }^{+}$and [PAT $]^{-}$, respectively. The corresponding calculated spectra are consistent with the observed excitation spectra of [PAST $]^{+}$and [PAT] ${ }^{-}$in PBS (Fig. S15, ESI $\dagger$ ). The Job-plot further demonstrates this reaction with a $1: 1$ ratio (Fig. S16, ESI $\dagger$ ), similar to the previously reported nucleophilic addition reaction. ${ }^{58,59}$

Subsequently the response of $[\mathbf{P A S T}]^{+}$to $\mathrm{HSO}_{3}{ }^{-}$was investigated in DNA enrichment buffer, which is PBS containing 6.0 $\mu \mathrm{M}$ duplex DNA (dsDNA, $5^{\prime}-\mathrm{C}_{1} \mathrm{~T}_{2} \mathrm{~T}_{3} \mathrm{~T}_{4} \mathrm{~T}_{5} \mathrm{G}_{6} \mathrm{C}_{7} \mathrm{~A}_{8} \mathrm{~A}_{9} \mathrm{~A}_{10} \mathrm{~A}_{11} \mathrm{G}_{12}-3^{\prime}$ ) (Fig. S17A, ESI $\dagger$ ). Fluorescence titration data indicate the binding constant $K_{\mathrm{a}}=5.1 \times 10^{6} \mathrm{~mol}^{-1}$ (Fig. S17B, ESI $\dagger$ ). The DNA/[PAST $]^{+}$stoichiometry has been determined from the Jobplot to be $1: 2$ (Fig. S17C, ESI $\dagger$ ), meaning that 2 molecules of [PAST] $^{+}$bind with 1 molecule of 12 mer DNA. Upon $\mathrm{HSO}_{3}{ }^{-}$ titration, the absorption at $345 \mathrm{~nm}$ and $515 \mathrm{~nm}$ gradually decreases and a new absorption peak emerges at $425 \mathrm{~nm}$

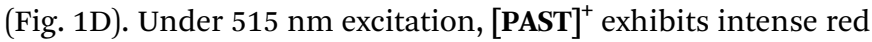
emission centered at $665 \mathrm{~nm}$, which also gradually decreases upon $\mathrm{HSO}_{3}{ }^{-}$titration similar to that in PBS without DNA (Fig. S18, ESI $\dagger$ ). However, under $405 \mathrm{~nm}$ excitation it is appealing to observe a new band appearing and gradually blueshifting ( $c a .115 \mathrm{~nm}$ ) to $565 \mathrm{~nm}$ accompanied by reduced emission at $665 \mathrm{~nm}$, the iso-emission point of which is at 625 $\mathrm{nm}$ (Fig. 1E). Moreover, the LOD value of [PAST] ${ }^{+}$for $\mathrm{SO}_{2}$ derivatives in the DNA enrichment environment is determined to be $320 \mathrm{nM}$ (Fig. S13B, ESI $\dagger$ ). There is a good linear relation$\operatorname{ship}\left(R^{2}=0.997\right)$ between the emission intensity ratio $I_{565} / I_{665}$ of [PAST] ${ }^{+}$and $\mathrm{HSO}_{3}{ }^{-}$concentrations in the range of $10-100 \mu \mathrm{M}$ (Fig. $1 \mathrm{H})$. When we changed the concentrations of [PAST] ${ }^{+}(5$ $\mu \mathrm{M}, 10 \mu \mathrm{M}$, and $20 \mu \mathrm{M}$ ), the linear relationship between the $\mathrm{HSO}_{3}{ }^{-} /[\mathbf{P A S T}]^{+}$equivalent and the fluorescence ratio overlaps (Fig. S19†). Accordingly, this calibration curve can be used for calculating $\mathrm{SO}_{2}$ derivatives in solution experiments. Similar ratiometric fluorescence response $\left(\lambda_{\mathrm{ex}}=405 \mathrm{~nm}\right)$ of $[\mathbf{P A S T}]^{+}$ toward $\mathrm{HSO}_{3}{ }^{-}$is also observed in calf thymus DNA (ctDNA, $40 \mu \mathrm{g}$ $\mathrm{mL}^{-1}$ ) enrichment buffer (Fig. S20, ESI $\dagger$ ), and the response is completed in $10 \mathrm{~min}$ (Fig. S21, ESI $\dagger$ ). The new peaks produced by [PAST $]^{+}$reacting with $\mathrm{HSO}_{3}{ }^{-}$in enrichment buffer coincide with the new peaks produced by [PAT $]^{-}$binding with DNA (Fig. S22, $\mathrm{ESI} \dagger)$. By contrast, the ratiometric phenomenon $\left(\lambda_{\text {ex }}=405 \mathrm{~nm}\right)$ was not observed in PBS, $40 \%$ PEG $_{200}$ solution (mimicking the crowded environment in nuclei), ${ }^{60}$ RNA (56 $\left.\mu \mathrm{g} \mathrm{mL}^{-1}\right)$ enrichment buffer, and HSA ( $56 \mu \mathrm{g} \mathrm{mL}{ }^{-1}$ ) enrichment buffer, thus excluding the interference of nuclear viscosity, RNA binding and nonspecific protein-probe association, respectively (Fig. S23 and S24, ESI $\dagger$ ). These results demonstrate that $[\mathbf{P A S T}]^{+}$can be utilized for ratiometric sensing of $\mathrm{SO}_{2}$ derivatives in a DNA enriched environment, for example the cellular nucleus.

\section{Selectivity of $[\mathrm{PAST}]^{+}$toward $\mathrm{SO}_{2}$ derivatives and $\mathrm{pH}^{-}$ dependency}

The fluorescence response of $[\mathbf{P A S T}]^{+}(10 \mu \mathrm{M})$ to various biologically relevant analytes was investigated, including various reactive sulfur species $\left(\mathrm{S}_{2} \mathrm{O}_{8}{ }^{2-}, \mathrm{SO}_{4}{ }^{2-}, \mathrm{S}_{2} \mathrm{O}_{3}{ }^{2-}\right.$, and $\left.\mathrm{HS}^{-}\right)$, reactive oxygen and nitrogen species $\left(\mathrm{H}_{2} \mathrm{O}_{2}, \mathrm{ClO}^{-}, \mathrm{ClO}_{4}{ }^{-}, \mathrm{NO}_{2}{ }^{-}\right.$, $\mathrm{NO}_{3}{ }^{-}, \mathrm{NH}_{4}{ }^{+}$, and $\mathrm{CN}^{-}$), bio-relevant species (Cys, GSH, EDTA, and citric acid) and several common anions $\left(\mathrm{F}^{-}, \mathrm{Cl}^{-}, \mathrm{HCO}_{3}{ }^{-}\right.$, $\mathrm{HPO}_{4}{ }^{2-}, \mathrm{OH}^{-}, \mathrm{C}_{2} \mathrm{O}_{4}{ }^{2-}$, and $\mathrm{CH}_{3} \mathrm{COO}^{-}$), at 200-times higher concentrations $(2.0 \mathrm{mM})$ than that of $\mathrm{HSO}_{3}{ }^{-} / \mathrm{SO}_{3}{ }^{2-}(10 \mu \mathrm{M})$. As shown in Fig. 1C and F, none of these analytes could change the fluorescence of [PAST] ${ }^{+}$either in the absence of DNA $\left(I_{0} / I\right)$ or in the presence of DNA $\left(I_{565} / I_{665}\right)$, indicating the good selectivity of [PAST] ${ }^{+}$toward $\mathrm{SO}_{2}$ derivatives. The selectivity was further confirmed by competition experiments, in which [PAST] ${ }^{+}(10$ $\mu \mathrm{M})$ was mixed with various biologically relevant analytes (2.0 $\mathrm{mM})$ with or without DNA $\left(40 \mu \mathrm{g} \mathrm{mL}{ }^{-1}\right)$, and then $\mathrm{SO}_{2}$ derivatives were added and the fluorescence response was monitored. It is found that fluorescence changes of [PAST] ${ }^{+}$in the absence of DNA $\left(I_{0} / I\right)$ or the presence of DNA $\left(I_{565} / I_{665}\right)$ are only observed when $\mathrm{SO}_{2}$ derivatives are present, indicating that all the tested biologically relevant analytes will not affect the fluorescence response even at concentrations as high as $2.0 \mathrm{mM}$ (Fig. S25, ESI†).

Considering that $\mathrm{SO}_{3}{ }^{2-}$ and $\mathrm{HSO}_{3}{ }^{-}$have a chance to reach $\mathrm{pH}$-equilibrium in aqueous solution and the intracellular $\mathrm{pH}$ values vary in the range of 5.0-8.0, we also investigated the $\mathrm{pH}$ effect on the fluorescence responsiveness of [PAST] ${ }^{+}$toward $\mathrm{SO}_{2}$ derivatives. In the absence of DNA, the red emission from $[\mathbf{P A S T}]^{+}$is always significantly quenched at $\mathrm{pH}=5.0$ and $\mathrm{pH}=$ 8.0 upon $\mathrm{NaHSO}_{3}$ addition, indicating the occurrence of the addition reaction and the formation of [PAT $]^{-}$(Fig. S26, $\operatorname{ESI} \dagger$ ). However, the addition reaction rate is $\mathrm{pH}$-dependent and is much slower in acidic solution than that in neutral and alkaline solution. For example, the addition reaction is completed in 10 min at pH 5.0,1 min at pH 7.4 and 1.5 min at pH 8.0 (Fig. 1G). In DNA enrichment buffer, similar ratiometric fluorescence response of $[\mathbf{P A S T}]^{+}$to $\mathrm{NaHSO}_{3}$ titration is observed at $\mathrm{pH}=5.0$ and $\mathrm{pH}=8.0$, indicating its potential for use in a cellular environment with varied $\mathrm{pH}$ values (Fig. S26, ESI†). Also the ratiometric fluorescence response is much slower in acidic solution (e.g. $60 \mathrm{~min}$ at $\mathrm{pH} 5.0$ ) than in neutral $(10 \mathrm{~min}$ at $\mathrm{pH}$ 7.4) and alkaline solution (8 $\mathrm{min}$ at $\mathrm{pH} 8.0$ ), as shown in Fig. $1 \mathrm{G}$. All these pH-dependency experiments demonstrate that although the addition reaction rates in the absence and presence of DNA are both pH-dependent (slower in acidic solution), the ratiometric fluorescent response of $[\mathbf{P A S T}]^{+}$selectively toward $\mathrm{SO}_{2}$ derivatives always works in the cellular $\mathrm{pH}$ range.

\section{Ratiometric fluorescence mechanism in a DNA enriched environment}

To further understand the binding mode of the probe to DNA, we also performed NMR (1D and 2D) and circular dichroism (CD) spectroscopy of DNA in the absence and presence of

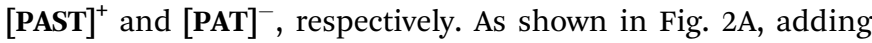
[PAST] $^{+}$in a DNA solution at $\mathrm{pH} 7.4$ led to notable line broadening of DNA signals, indicative of a medium or fast exchange rate on the NMR time scale. In addition, small but interesting chemical shift changes were observed in the $\mathrm{H} 1 / \mathrm{H} 3$ proton signals of the $\mathrm{T}_{4}, \mathrm{~T}_{5}$, and $\mathrm{G}_{24}$. [PAST] $]^{+}$titration was performed 
only in the concentration range of 0.0-1.0 equivalents because a higher concentration of [PAST $]^{+}$leads to DNA precipitation. In contrast, significant chemical shift changes in the $\mathrm{H} 1 / \mathrm{H} 3$ proton signals of the $T_{2}, T_{3}, T_{4}, T_{5}$, and $G_{6}$ as well as line broadening were observed for [PAT $]^{-}$titration into DNA under the same conditions. Corresponding 2D H-H NOESY spectra were also collected. Consistent with the 1D NMR spectra, severe line broadening was observed for [PAST] $^{+}$binding (Fig. S27,
A

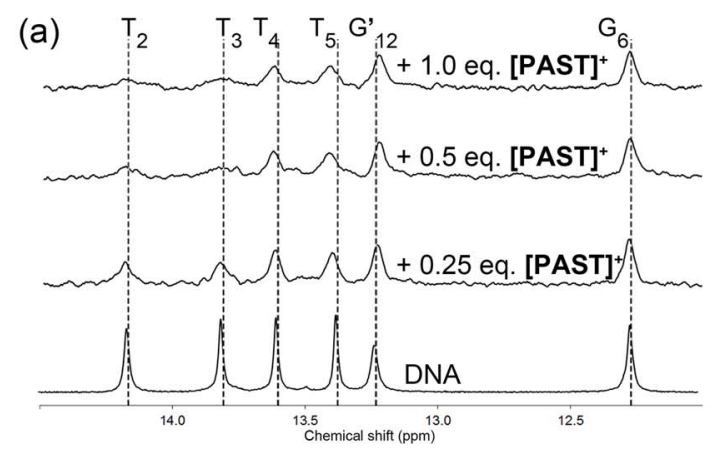

(b)

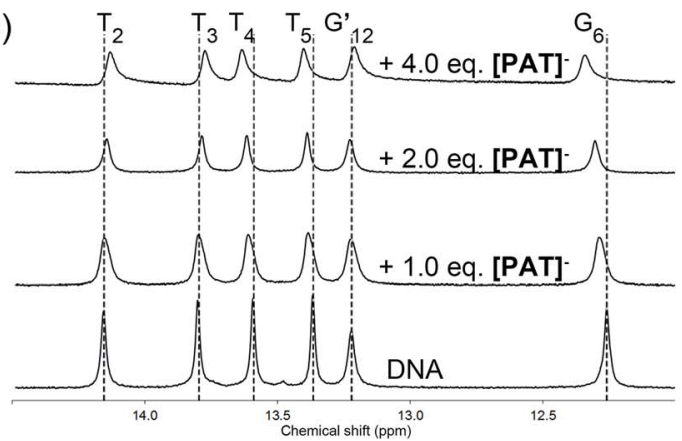

B (a)

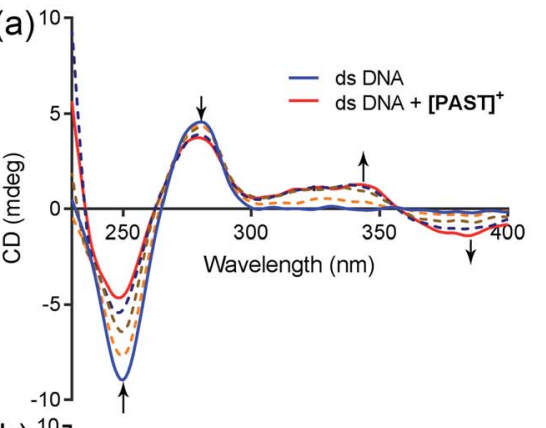

(b)
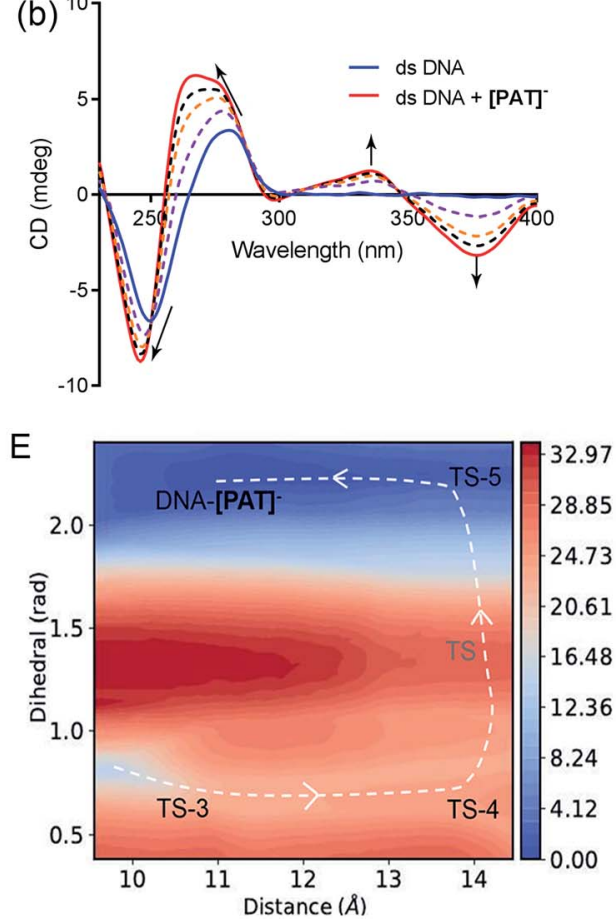

C

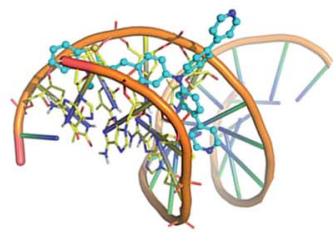

DNA-[PAST] ${ }^{+}$(Bind-2)

D

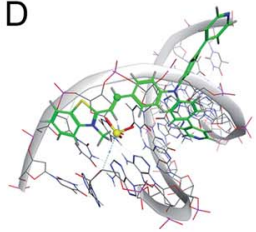

DNA-[PAST]+

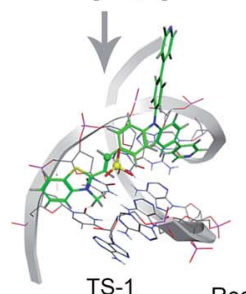

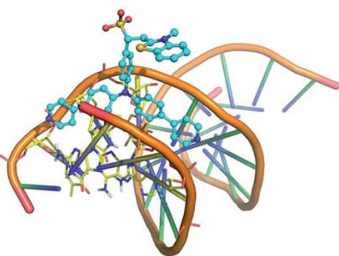

DNA-[PAT] ${ }^{-}$(Bind-1)

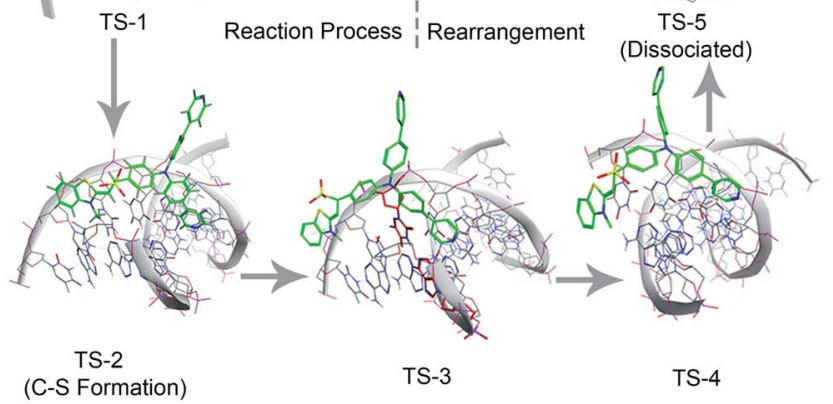

(C-S Formation)
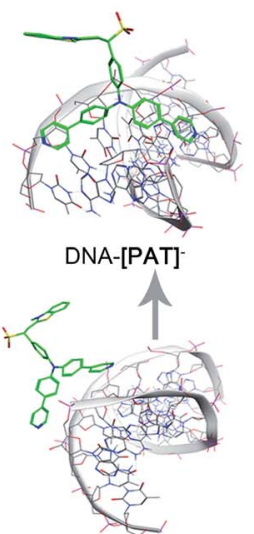

TS-4

Fig. 2 (A) ${ }^{1} \mathrm{H}$ NMR spectra of dsDNA in buffer solution $\left(\mathrm{D}_{2} \mathrm{O}: \mathrm{H}_{2} \mathrm{O}=1: 9,5^{\circ} \mathrm{C}\right)$ in the presence of [PAST] ${ }^{+}$and [PAT] ${ }^{-}$, respectively; $(B) \mathrm{CD}$ spectra of dsDNA in PBS buffer solution in the presence of increasing concentrations of [PAST $]^{+}$and [PAT] $^{-}$, respectively; (C) the most stable binding modes of the DNA-[PAST $]^{+}$complex and DNA-[PAT $]^{-}$complex. See Fig. S29 in ESI $\uparrow$ for other binding modes with binding energies. The nucleotides $T_{2}, T_{3}, T_{4}, T_{5}, A_{21}, A_{22}$ and $A_{23}$ were colored in blue/yellow and highlighted in the stick model; (D) QM/MM simulations of the nucleophilic addition reaction process and the subsequent conformational rearrangement; $(E)$ the two-dimensional free energy map of the conformational rearrangement process with two defined reaction coordinates, which are the distance $(\AA)$ between the core $\mathrm{N}$ atom in the tripod and the centroid of the nucleotides $\mathrm{A}_{21}$ and $\mathrm{T}_{4}$ in the DNA system and the dihedral angle (rad) between two 4-phenylpyridine rings, respectively. The energy is in units of kcal mol $^{-1}$ and the interval between two consecutive contours is $1.0 \mathrm{kcal} \mathrm{mol}^{-1}$. 
ESI $\dagger$ ). Signal shifts and some new NOE signals were observed after [PAT] ${ }^{-}$binding (Fig. S28, ESI $\dagger$ ). Although the line broadening in the NMR spectra prevents the detailed structural analysis of DNA-[PAST $]^{+}$and DNA- $[\mathbf{P A T}]^{-}$complexes, the different chemical shift changes demonstrated that $[\mathbf{P A S T}]^{+}$and [PAT] $]^{-}$binding led to different conformational changes of DNA, indicative of distinct binding modes of these two molecules to DNA.

In CD spectra (Fig. 2B), dsDNA is characterized by a positive band at $\sim 275 \mathrm{~nm}$ and a negative band at $\sim 245 \mathrm{~nm}$, indicative of base stacking and the right-handed helix structure, respectively. With increasing concentrations of [PAST $]^{+}$, both peak signals gradually weaken, indicating that DNA-[PAST $]^{+}$interaction can change the helical nature of DNA and cause DNA unwinding, so that it may be an external binding manner rather than classical intercalation. The newly emerged positive band at $\sim 340 \mathrm{~nm}$ and negative band at $\sim 380 \mathrm{~nm}$ indicate a minor groove binding which is consistent with the molecular docking results. By contrast, with increasing concentrations of [PAT $]^{-}$, both negative $(\sim 245 \mathrm{~nm})$ and positive $(\sim 275 \mathrm{~nm})$ peaks of DNA are greatly enhanced and blue-shifted, indicating that DNA-[PAT $]^{-}$interaction can enhance the stacking between bases and stabilize the right-handed superhelix structure. Meanwhile, the newly emerged positive and negative peak signals are also observed at $\sim 340 \mathrm{~nm}$ and $\sim 380 \mathrm{~nm}$ indicative of the occurrence of minor groove binding. The different changes in the CD spectra of DNA induced by $[\mathbf{P A S T}]^{+}$and $[\mathbf{P A T}]^{-}$indicate that both compounds can alter the helical nature of DNA and affect the base accumulation of DNA but in a different manner, which is indicative of distinct bonding modes of these two molecules to DNA (Fig. 2B).

In order to authenticate the ratiometric sensing mechanism,

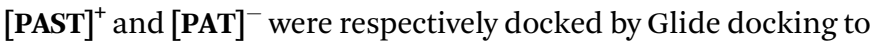
a 12-mer dsDNA $\left(5^{\prime}-\mathrm{C}_{1} \mathrm{~T}_{2} \mathrm{~T}_{3} \mathrm{~T}_{4} \mathrm{~T}_{5} \mathrm{G}_{6} \mathrm{C}_{7} \mathrm{~A}_{8} \mathrm{~A}_{9} \mathrm{~A}_{10} \mathrm{~A}_{11} \mathrm{G}_{12}-3^{\prime}\right)$, which had exactly the same base sequence as that used in the experiments, and the docked poses were ranked by XP scoring. MM/ MD simulations give four highest scored binding modes with various binding free energies as shown in Fig. S29, (ESI $\dagger$ ), and among them two binding modes DNA-[PAST $]^{+}$Bind-2 and DNA-[PAT $]^{-}$Bind-1 are shown in Fig. $2 \mathrm{C}$ as typical examples. Based on the energy decomposition, hydrophobic interactions and stacking between DNA nucleotides and the aromatic rings of tripods allow the formation of DNA-[PAST $]^{+}$and DNA-[PAT $]^{-}$ complexes, and the nucleotides $\mathrm{T}_{2}, \mathrm{~T}_{3}, \mathrm{~T}_{4}, \mathrm{~T}_{5}, \mathrm{~A}_{21}, \mathrm{~A}_{22}$ and $\mathrm{A}_{23}$ always exhibit a stronger interaction force than other nucleotides. Thus $[\mathbf{P A S T}]^{+}$and $[\mathbf{P A T}]^{-}$share the same binding position (minor groove) in the DNA system. Such favorable binding also likely arises from a nice shape complementarity between the DNA groove and the tripodal structure.

Although $[\mathbf{P A S T}]^{+}$and $[\mathbf{P A T}]^{-}$share the same DNA skeleton, the calculated binding energy indicate the stronger DNA binding of $[\mathbf{P A S T}]^{+}$than of $[\mathbf{P A T}]^{-}$. More interestingly, these two tripods have distinct DNA binding modes. For the DNA-[PAST] ${ }^{+}$ complex, the benzothiazole group in [PAST] ${ }^{+}$has a better DNA binding affinity than the 4-phenylpyridine since the positive charge in benzothiazole has a strong Coulomb attraction force with the phosphate backbones of DNA. Thus [PAST] ${ }^{+}$prefers to bind with DNA via the benzothiazole moiety and one 4-phenylpyridine arm to form a stable DNA-[PAST $]^{+}$complex (Bind-1, -2 , and -3 in Fig. $2 \mathrm{C}$ and S29A, ESI $\dagger$ ). As for the DNA-[PAT] ${ }^{-}$ complex, the negative charge of the sulfite ion results in a Coulomb repulsion force between the benzothiazole- $\mathrm{SO}_{2}$ group and DNA backbone, resulting in significantly reduced binding energies which make the DNA-[PAT $]^{-}$partially (Bind-1 and Bind-2 in Fig. S29B, ESI $\dagger$ ) or completely dissociate (Bind-3 and -4 in Fig. S29G, ESI $\dagger$ ). The most stable DNA-[PAT $]^{-}$complex (Bind-1 in Fig. 2C and S29B, ESI $\dagger$ ) shows that [PAT $]^{-}$uses both of the 4-phenylpyridine groups to bind with DNA while the benzothiazole- $\mathrm{SO}_{2}$ moiety stretches out. The distinct binding modes of DNA-[PAST $]^{+}$and DNA- $[\mathbf{P A T}]^{-}$indicate a conformational rearrangement of the DNA-tripod complex after the sulfite ion addition reaction.

Furthermore, QM/MM simulations were performed to investigate the detailed process of the nucleophilic addition reaction and the DNA binding mode rearrangement (Fig. 2D). Herein, although [PAST $]^{+}$Bind-1 has a lower binding free energy, the nucleophilic carbon orienting inside the DNA system impedes the attack of the sulfite ion, making Bind-1 less suitable for the sulfite ion addition reaction. Thus $[\mathbf{P A S T}]^{+}$Bind2 obtained in the MM/MD simulations is chosen as the initial structure for the QM/MM simulations. The relative potential energy surface in Fig. S30 (ESI $\dagger$ ) shows that the energy barrier of sulfite ion addition reaction is $c a .9 \mathrm{kcal} \mathrm{mol}^{-1}$, which is feasible in biological systems, and in the view of thermodynamics this is an exothermal reaction releasing ca. $16 \mathrm{kcal} \mathrm{mol}^{-1}$ energy. The transition state structures obtained in QM/MM simulations show that at the beginning of the nucleophilic addition reaction, the oxygens in the sulfite ion first flip over (TS-1) and then the carbon sulfur bond is formed (TS-2) to generate [PAT] ${ }^{-}$. Due to the Coulomb repulsion between the negatively charged benzothiazole- $\mathrm{SO}_{2}$ group and DNA backbone, this transition state has a very short life time $(<100 \mathrm{~ns})$ and the DNA-[PAT] ${ }^{-}$ binding mode rearrangement is expected to occur right after the addition reaction. TS-2 gradually dissociates with the less stable DNA- $[\mathbf{P A T}]^{-}$Bind-2 as a partially dissociated state (TS-3). Then after complete dissociation (TS-5), the ligands of [PAT $]^{-}$become free to rotate in the solvent, and once the negatively charged benzothiazole- $\mathrm{SO}_{2}$ group rotates away from the DNA system, the free energy decreases a lot. The barrier of this rotation is about $7 \mathrm{kcal} \mathrm{mol}^{-1}$ and it releases ca. $15 \mathrm{kcal} \mathrm{mol}^{-1}$. After the rotation $[\mathbf{P A T}]^{-}$seizes back DNA while releasing another $1 \mathrm{kcal}$ $\mathrm{mol}^{-1}$, generating the most stable DNA-[PAT $]^{-}$complex (Bind1). Such a feasible and exothermal binding mode rearrangement to produce DNA-[PAT $]^{-}$Bind-1 is indicated by the twodimensional free energy map shown in Fig. 2E. To further evaluate whether the negatively charged responsive arm is required for the charge-driven tripod somersault on DNA, we synthesized a control compound, TPPA, possessing a symmetric structure with three phenyl-pyridyl groups but without a responsive group (Fig. S29F, ESI $\dagger$ ). This compound only exhibits one DNA binding mode via two phenyl-pyridyl arms with a binding free energy of $-16.7 \mathrm{kcal} \mathrm{mol}^{-1}$, and its DNA binding capability can be confirmed by the significantly (40fold) enhanced fluorescence in the DNA titration experiment. 
This provides additional evidence confirming that $[\mathbf{P A T}]^{-}$ binding with DNA via two neutral phenyl-pyridyl arms is very reasonable. We also performed $\mathrm{MM} / \mathrm{MD}$ simulations of neutral [HPAT $^{0}$ and protonated $\left[\mathbf{H}_{2} \mathbf{P A T}\right]^{+}$and $\left[\mathbf{H}_{3} \mathbf{P A T}\right]^{2+}$ compounds docked to the 12-mer dsDNA (Fig. S29C-E, ESI $\dagger$ ). It is found that the most stable DNA binding mode of [HPAT] ${ }^{0}$ is similar to that of [PAT $]^{-}$, in which the two phenyl-pyridyl arms bind with DNA at minor grooves, and their binding free energies $(-11.8$ and $-11.1 \mathrm{kcal} \mathrm{mol}^{-1}$ ) are also similar, indicating that an electronneutral responsive arm is sufficient for the change of the DNA binding mode. The positively charged $\left[\mathbf{H}_{2} \mathbf{P A T}\right]^{+}$and $\left[\mathbf{H}_{3} \mathbf{P A T}\right]^{2+}$ also exhibit similar DNA binding modes to neutral [HPAT] ${ }^{0}$ and $[\mathbf{P A T}]^{-}$but with stronger binding free energies $(-20.4$ and $-21.5 \mathrm{kcal} \mathrm{mol}^{-1}$ ), indicating that DNA-[PAT $]^{-}$might be more stable in an acidic microenvironment, which was consistent with the pH-dependency investigations in Fig. S29, ESI. $\dagger$

\section{Ratiometric fluorescence imaging of endogenous $\mathrm{SO}_{2}$ derivatives using $[\text { PAST }]^{+}$in the nucleus}

Subsequently, we used this strategy for in vitro and in vivo ratiometric fluorescence imaging of the variations of endogenous $\mathrm{SO}_{2}$ derivatives in the nucleus of living cells. At the cellular level, [PAST $^{+}(20 \mu \mathrm{M})$ can effectively enter living A549 cells in $20 \mathrm{~min}$ (Fig. S31, ESI $\dagger$ ), the intensive red emission of which exhibits a high degree of co-localization with the nucleus-specific stain Hoechst 33342 (Pearson's correlation coefficient is 0.96, Fig. 3A), but non-colocalization with LysoTracker or MitoTracker (Fig. S32, ESI $\dagger$ ), indicating the effective and specific accumulation of $[\mathrm{PAST}]^{+}$in the nucleus. Similar nuclear-specific accumulation is also observed in HeLa and PC3 cells (Fig. S33, ESI†). In the cytotoxicity experiment, A549 cells exposed to as high as $100 \mu \mathrm{M}$ [PAST $^{+}$for $6 \mathrm{~h}$ and $24 \mathrm{~h}$ still show cellular viability greater than $90 \%$ and $60 \%$, respectively (Fig. S34, ESI $\dagger$ ). When the imaging concentration $(20 \mu \mathrm{M})$ is performed, [PAST $]^{+}$induced alternations of intracellular ROS levels and mitochondria membrane potential after $6 \mathrm{~h}$ treatment are similar to those of control cells (Fig. S35 and S36, ESI $\dagger$ ); when the treatment time is increased $(12-24 \mathrm{~h}),[\mathrm{PAST}]^{+}$treated cells only exhibit 1.1 -fold higher intracellular ROS levels. Considering the interaction between $[\text { PAST }]^{+}$and DNA, we also investigated the influence of $[\text {PAST }]^{+}$on the A549 cell cycles by propidium iodide (PI) staining using flow cytometry. As shown in Fig. S37 (ESI $\dagger$ ), [PAST] ${ }^{+}(10$ and $20 \mu \mathrm{M})$ treated cells show similar cell cycles after 6-24 h incubation compared with the vehicle-treated cells, and exhibit only slight increases in the proportion of cells in the S-phase after 18-24 h incubation. These results indicate that although [PAST ${ }^{+}$has some long-term cytotoxicity, it will not induce alternations of the intracellular microenvironment or adverse effects at least during the imaging process.

Ratiometric fluorescence imaging of nuclear $\mathrm{SO}_{2}$ derivatives in A549 cells was performed in dual-emission mode $\left(\lambda_{\mathrm{ex}}=405\right.$ $\mathrm{nm}$ ) by mediating the yellow channel image (band path of $565 \pm$ $20 \mathrm{~nm}$ ) with the corresponding red channel image (band path of $665 \pm 20 \mathrm{~nm}$ ). It has been reported that biological sulphite can be produced endogenously from thiosulphate and GSH via thiosulphate sulphur transferase (TST) and can then be

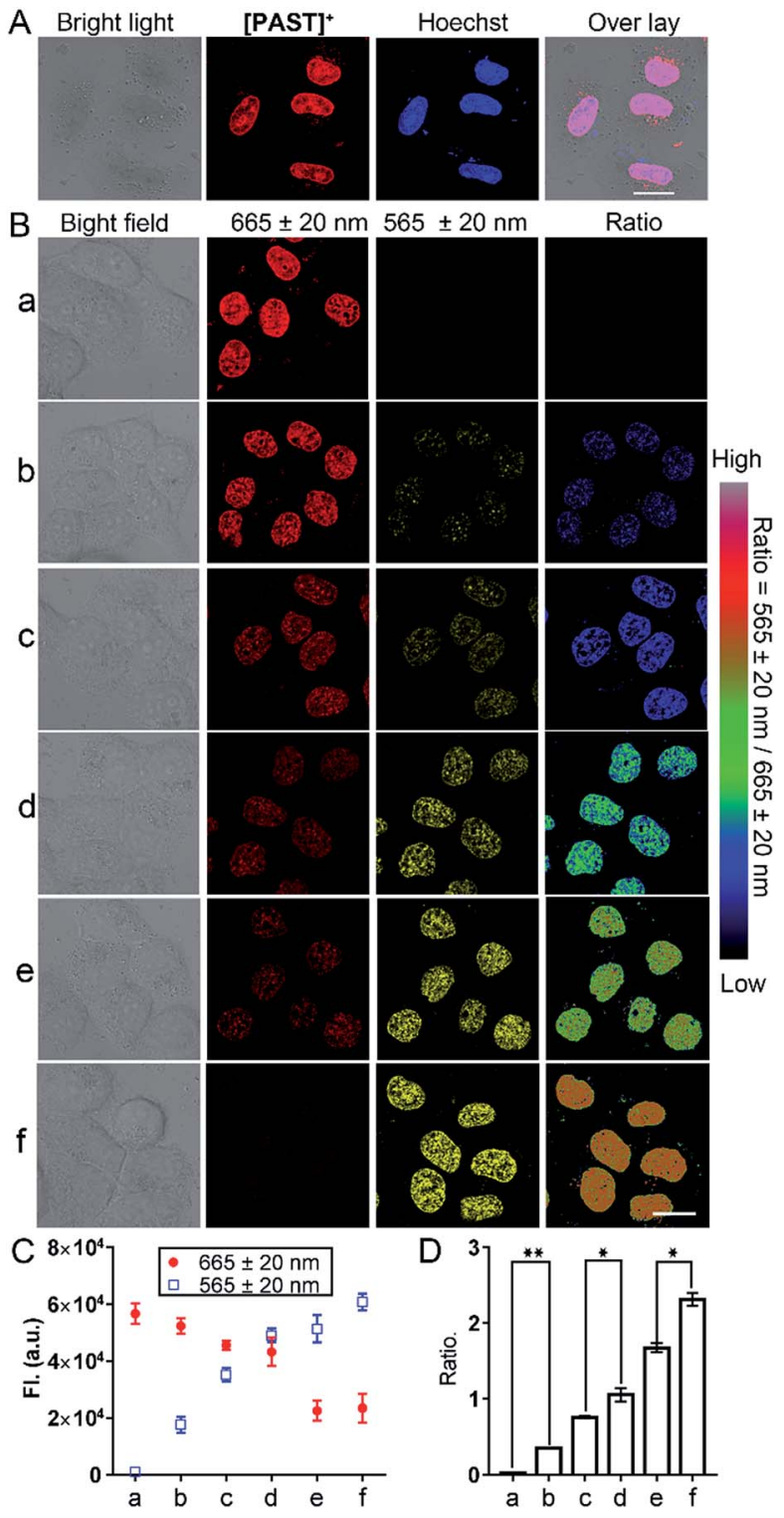

Fig. 3 (A) Colocalization between [PAST] $]^{+}$and the nucleus-specific stain Hoechst (Hoechst 33342) in living cells (probe: $\lambda_{\mathrm{ex}} / \lambda_{\mathrm{em}}=543 \mathrm{~nm} /$ $665 \pm 20 \mathrm{~nm}$; Hoechst: $\lambda_{\mathrm{ex}} / \lambda_{\mathrm{em}}=405 \mathrm{~nm} / 460 \pm 20 \mathrm{~nm}$ ). (B) Ratiometric fluorescence imaging of the variations of endogenous $\mathrm{SO}_{2}$ derivatives in the nucleus of living cells. A549 cells were incubated with [PAST] $^{+}(20 \mu \mathrm{M})$ for $20 \mathrm{~min}$ and then treated with thiosulphate/GSH at (a) $0 \mu \mathrm{M} / 0 \mu \mathrm{M}$ (control), (b) $60 \mu \mathrm{M} / 30 \mu \mathrm{M}$, (c) $120 \mu \mathrm{M} / 60 \mu \mathrm{M}$, (d) 180 $\mu \mathrm{M} / 90 \mu \mathrm{M}$, (e) $240 \mu \mathrm{M} / 120 \mu \mathrm{M}$, and (f) $300 \mu \mathrm{M} / 150 \mu \mathrm{M}$ (concentrations) for another 30 min to stimulate endogenous $\mathrm{SO}_{2}$ derivatives; scale bar: $20 \mu \mathrm{m}$. (C and D) The mean values of the fluorescence photon number collected from the red and yellow channel, respectively, and the ratio of their photon numbers were calculated. Data were calculated from 3-5 fields of view and each experimental condition was performed in triplicate. Data are represented as mean \pm SD of three independent experiments, $* * P<0.05, * P<0.02$.

converted to sulphate via sulphate oxidase in mammals..$^{61,62}$ It is worth mentioning that separately added thiosulphate or GSH will not induce the generation of endogenous $\mathrm{SO}_{2}$ derivatives, and thus will not affect the [PAST] ${ }^{+}$emission (Fig. S38, ESI†). Therefore A549 cells were stimulated with various concentrations of 
thiosulphate/GSH $(2: 1)$ for 30 min to induce different concentrations of endogenous $\mathrm{SO}_{2}$ derivatives. ${ }^{63,64}$ As shown in Fig. 3B, non-stimulated A549 cells stained with [PAST] $]^{+}(20 \mu \mathrm{M}, 20 \mathrm{~min})$ show intense fluorescence in the red channel and dim fluorescence in the yellow channel, giving a low $F_{\text {yellow }} / F_{\text {red }}$ ratio implying a very low sulfite/bisulfite level. However, after stimulating cells with increasing concentrations of thiosulphate/GSH, a distinct increase in yellow fluorescence is observed accompanied by a dramatic decrease in the red fluorescence, thus leading to a gradual increase of the ratiometric signals $\left(F_{\text {yellow }} / F_{\text {red }}\right)$. This indicates the gradually increased sulfite/bisulfite level in the nucleus. Each cellular imaging experiment was performed in triplicate under the same conditions with the same microscopic settings, and 3-5 fields of view were taken for each dish for calculating the mean values of fluorescence intensity with error bars and statistical significance (Fig. 3C and D). We have further investigated the effect of concentration of the probe on the ratiometric signals. A549 cells were incubated with different concentrations of [PAST] ${ }^{+}(10 \mu \mathrm{M}, 20 \mu \mathrm{M}$ and $30 \mu \mathrm{M})$ for $20 \mathrm{~min}$, as shown in Fig. S39 (ESI $\dagger$ ). The results show that the ratiometric signals changed obviously when the concentration of [PAST] ${ }^{+}$ changed from $10 \mu \mathrm{M}$ to $20 \mu \mathrm{M}$, but when the concentration of
[PAST] $]^{+}$changed from $20 \mu \mathrm{M}$ to $30 \mu \mathrm{M}$, the ratiometric signals almost did not change. In other words, [PAST] $]^{+}$at $10 \mu \mathrm{M}$ does not produce the same ratiometric signals in cells as it does at higher concentrations $(20-30 \mu \mathrm{M})$. This may be due to the restrictions of cell uptake. The same results were also obtained with HeLa cells.

Once cells were pre-treated with a thiosulphate sulphur transferase inhibitor, TNBS $(1.0 \mathrm{mM}, 2 \mathrm{~h})$, to prevent the generation of endogenous $\mathrm{SO}_{2}$ derivatives, the red emission from intracellular [PAST $]^{+}$did not show any changes with thiosulphate/ GSH $(500 \mu \mathrm{M} / 250 \mu \mathrm{M})$ stimulation (Fig. S38, ESI $\dagger$ ). This further demonstrates the reliability of the ratiometric fluorescence imaging of endogenous $\mathrm{SO}_{2}$ derivatives. It is worth mentioning that the ratiometric signals only represent the variations of nuclear rather than cytoplasmic sulfite/bisulfite levels, which can be confirmed by parallel experiments with [PAT $]^{-}$prepared in advance in solution (Fig. S40, ESI $\dagger$ ). Living cells incubated with [PAT $]^{-}$only show dim fluorescence; however, after PBS washing, culture medium refreshing, and cell permeation, the nuclei are lit up by yellow fluorescence. This demonstrates that even if [PAST] ${ }^{+}$ picks sulfite/bisulfite up on the way, the formed [PAT $]^{-}$in the cytoplasm only shows dim fluorescence and cannot enter the nuclei to interfere with the ratiometric signals.
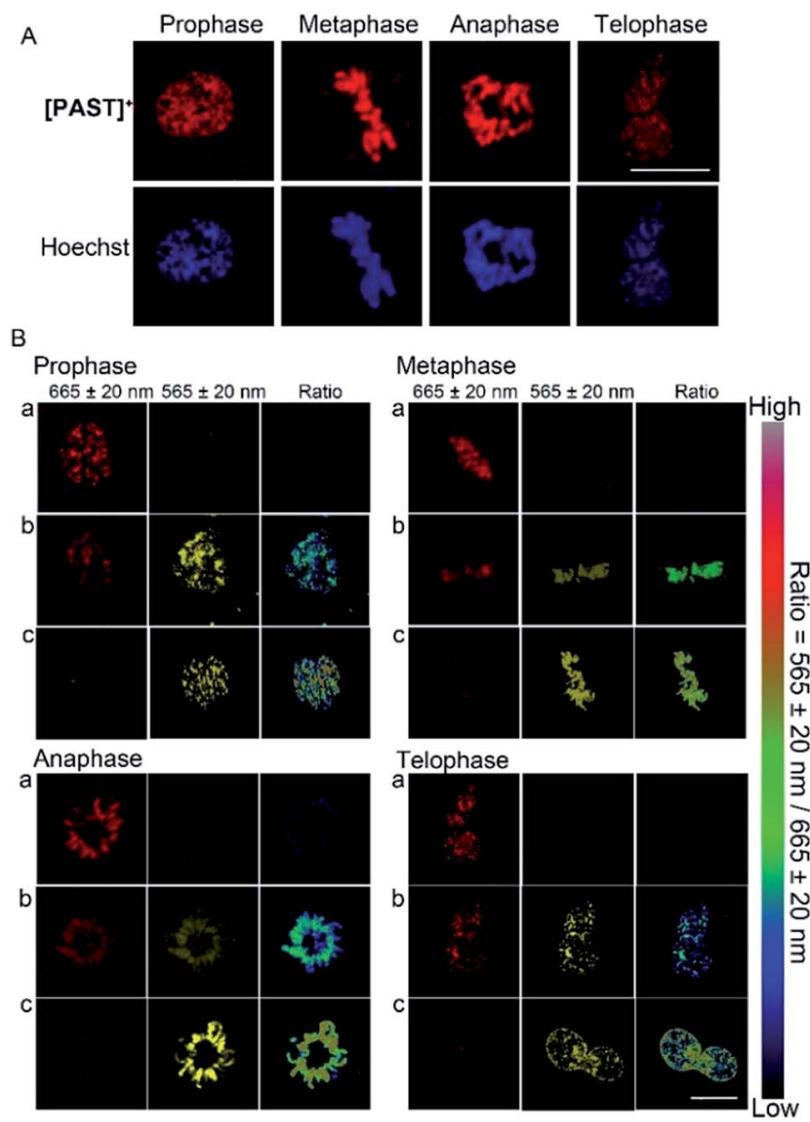

C

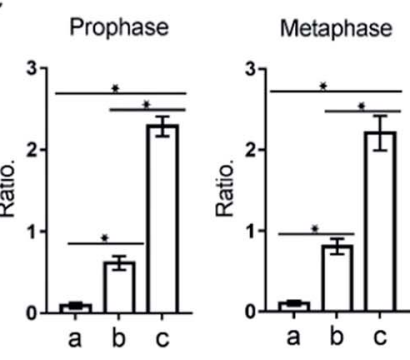

Fig. 4 (A) Confocal microscope images of single asynchronous cells co-stained with [PAST] ${ }^{+}$and the nucleus-specific stain Hoechst 33342. (B) Ratiometric fluorescence imaging of endogenous $\mathrm{SO}_{2}$ derivatives in living cells undergoing prophase, metaphase, anaphase and telophase, respectively. A549 cells during the split period were incubated with [PAST] $]^{+}(20 \mu \mathrm{M})$ for 20 min and then treated with thiosulphate/GSH at (a) $0 \mu \mathrm{M} / 0 \mu \mathrm{M}$, (b) $250 \mu \mathrm{M} / 125 \mu \mathrm{M}$, and (c) $500 \mu \mathrm{M} / 250 \mu \mathrm{M}$ for another 30 min to stimulate endogenous SO${ }_{2}$ derivatives; scale bar: $10 \mu \mathrm{m}$. (C) The mean values of the ratiometric fluorescence intensity obtained from different division phases. Data are represented as mean $\pm \mathrm{SD}$ of three independent experiments, $* P<0.02$. 

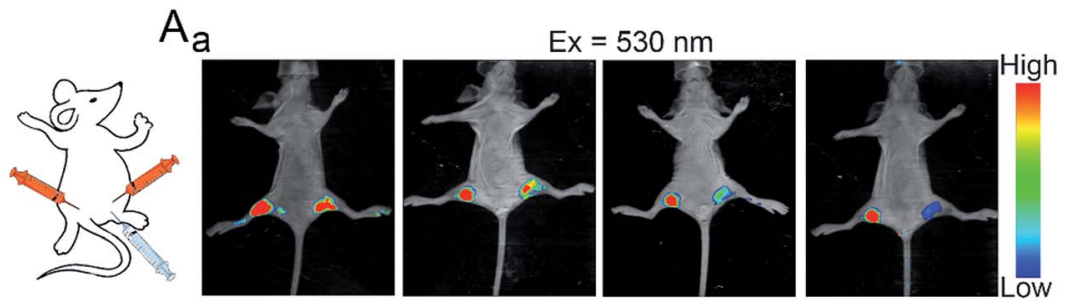

b
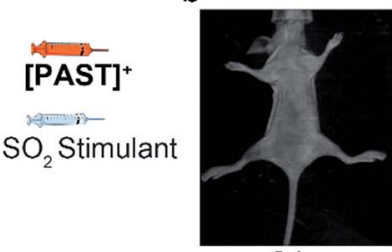

$0 \mathrm{~h}$

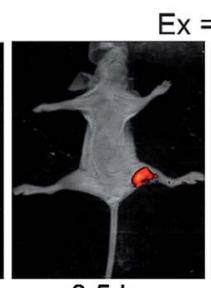

$0.5 \mathrm{~h}$

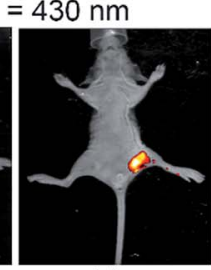

$1 \mathrm{~h}$

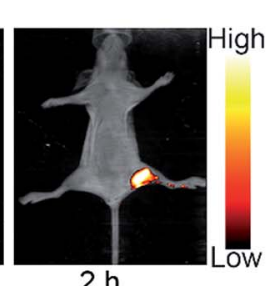

$2 \mathrm{~h}$
B

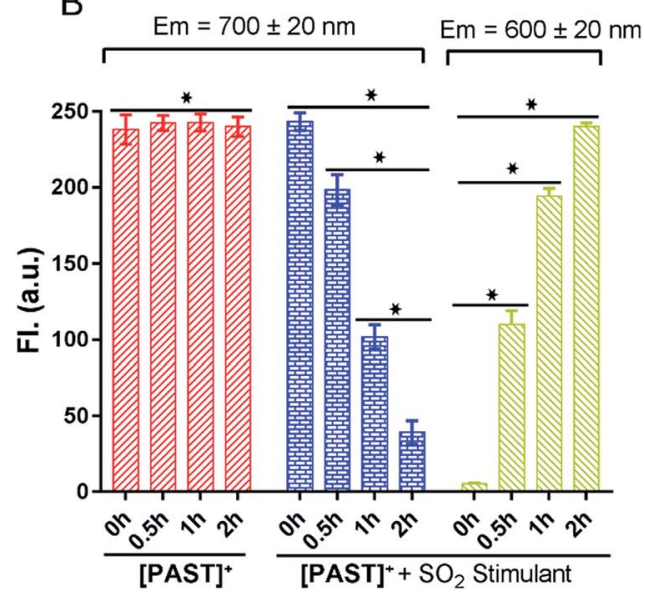

Fig. 5 (A) In vivo time-dependent fluorescence images for visualizing endogenous $\mathrm{SO}_{2}$ derivatives. $\lambda_{\mathrm{em}}=700 \pm 20 \mathrm{~nm}$ (a); $\lambda_{\mathrm{em}}=600 \pm 20 \mathrm{~nm}$ (b). The probe [PAST] $^{+}$(con. $20 \mu \mathrm{M}$ ) was injected into the thigh roots (both left and right) of living nude mice; 30 min later, thiosulphate/GSH (1.0 $\mathrm{mM} / 500 \mu \mathrm{M}$ ) was injected into the right thigh root only to stimulate endogenous $\mathrm{SO}_{2}$ derivatives while the left thigh was used as a control without stimulation. (B) The mean values of the fluorescence intensity calculated from the red channel of the probe (left thigh root, $\lambda_{\mathrm{em}}=700 \pm$ $20 \mathrm{~nm}$ ) and the red channel (right thigh root, $\lambda_{\mathrm{em}}=700 \pm 20 \mathrm{~nm}$ ) and yellow channel (right thigh root, $\lambda_{\mathrm{em}}=600 \pm 20 \mathrm{~nm}$ ) of the probe $+\mathrm{SO}_{2}$ stimulant, respectively. Data are collected from three mice and represented as mean \pm SD of three independent experiments, $* P<0.02$.

Furthermore, $[\text { PAST }]^{+}$can also visualize variations of sulfite/ bisulfite levels on chromosomes with various structural variations of nuclear rather than cytoplasmic sulfite/bisulfite levels, which can be confirmed by parallel characteristics. This is exciting because $\mathrm{SO}_{2}$ directly relates to chromosomal aberrations and sister chromatid exchanges. ${ }^{11,51}$ As shown in the higher resolution micrographs of single cells, when asynchronous cells are imaged, $[\text { PAST }]^{+}$is always co-localized with chromosomes as cells progress through the cell cycle (Fig. 4), and ratiometric fluorescence images in living cells undergoing prophase, metaphase, anaphase and telophase can be obtained as an indication of local chromosomal $\mathrm{SO}_{2}$ derivatives (Fig. 4B). Mean values of every single sample taken from 3-5 fields of view were calculated and are shown as bar graphs with error bars and statistical significance in Fig. 4C. Considering the important role of DNA in this ratiometric sensing strategy, we also used nuclease-treated A549 cells, in which most nucleic acids were digested. As shown in Fig. S41 (ESI $\dagger$ ), the red fluorescence from $[\mathbf{P A S T}]^{+}$in nuclease-treated cells is much weaker than that in control cells and mostly distributed in the cytoplasm. After incubating the nuclease-treated cells with 200 $\mu \mathrm{M} \mathrm{NaHSO}$ for $30 \mathrm{~min}$, a distinct decrease in the red channel fluorescence is observed without the ratiometric phenomenon. These results further confirm that DNA is an indispensable factor in this ratiometric fluorescence imaging strategy.

\section{Ratiometric fluorescence imaging of endogenous $\mathrm{SO}_{2}$ derivatives using $[\text { PAST }]^{+}$in vivo}

Lastly, the feasibility of [PAST $]^{+}$for in vivo imaging of endogenous $\mathrm{SO}_{2}$ derivatives was also investigated. [PAST] ${ }^{+}(20 \mu \mathrm{M}, 300$ $\mu \mathrm{L}$ ) was injected into the thigh roots (both left and right) of living nude mice; $30 \mathrm{~min}$ later, thiosulphate/GSH $(1.0 \mathrm{mM} / 500$ $\mu \mathrm{M}, 300 \mu \mathrm{L}$ ) was solely injected into the right thigh to stimulate endogenous $\mathrm{SO}_{2}$ derivatives while the left thigh was injected with $300 \mu \mathrm{L}$ PBS as a control. As shown in Fig. 5A(a), under 530 $\mathrm{nm}$ excitation, the fluorescence intensity in the left thigh (control) does not change during the measurement whereas that in the right thigh is gradually quenched in $2 \mathrm{~h}$. This is consistent with the reduced $F_{\text {red }}$ channel observed in the cellular experiment (Fig. 3). Simultaneously, under $430 \mathrm{~nm}$ excitation (Fig. $5 \mathrm{~A}(\mathrm{~b})$ ), the fluorescence intensity in the left thigh (control) is negligible whereas that in the right thigh root is gradually enhanced in $2 \mathrm{~h}$. This is consistent with the gradually increased $F_{\text {yellow }}$ channel observed in living cells (Fig. 3). Mean values of fluorescence signals were calculated for three mice per condition, shown as bar graphs with error bars and statistical significance (Fig. 5B). These data demonstrate that [PAST ${ }^{+}$can be used for measuring the variations of endogenous $\mathrm{SO}_{2}$ derivatives in vivo in a ratiometric fluorescence manner.

\section{Conclusions}

In summary, we take advantage of the DNA enriched environment in the nucleus to establish a ratiometric fluorescence imaging strategy, the so called "charge-driven tripod somersault on DNA". Based on this, a nucleus-targeted tripod [PAST] ${ }^{+}$has been synthesized by conjugating two DNA binding agents containing a reaction site for the target analyte. Once the DNA$[\text { PAST }]^{+}$reacts with the negatively charged target analyte, the newly formed tripod [PAT $]^{-}$binds DNA with different binding modes, thus resulting in the disappearance of the first emission feature from DNA-[PAST $]^{+}$and the emergence of the second emission feature from DNA-[PAT] $]^{-}$. By using this, we realized the in vitro and in vivo ratiometric fluorescence imaging of endogenous $\mathrm{SO}_{2}$ derivatives in the nucleus for the first time. In theory, as long as the analyte could react with the responsive group and change the charge of the responsive arm of the tripodal probe, the tripod somersault could occur to realize the ratiometric fluorescence imaging. Moreover, the change from 
positive-to-negative charge is not necessary and the analyteinduced formation of an electron-neutral responsive arm is sufficient for the change of the DNA binding mode. Therefore, we anticipate that this strategy can be further extended for ratiometric fluorescence imaging of a wide range of bioactive molecules in the nucleus. Although $[\mathbf{P A S T}]^{+}$has some long-term cytotoxicity, it will not induce alternations of the intracellular microenvironment or adverse effects at least during the imaging process. Further modification may help to improve the biocompatibility of the tripodal probe, e.g. methylation and tertbutylation of the phenyl-pyridine arms, which is also helpful for avoiding the pH dependency of the probe. Furthermore, since the charge-driven tripod somersault on DNA is feasible, this "somersault on DNA" strategy can also be extended to other structures, such as triangles, propellers, clovers, and multi-arm structures with inherent nucleic acid binding capacity. This provides an opportunity for opening up a new avenue for the design of nucleus-localised responsive probes for biological analytes.

\section{Conflicts of interest}

There are no conflicts to declare.

\section{Acknowledgements}

This work was financially supported by the National Natural Science Foundation of China [21837006, 21572282 and 21401217], the Ministry of Education of China (No. IRT17R111), 973 Program [2014CB845604, 2015CB856301], Natural Science Foundation of Guangdong Province [2017A030313041], Fundamental Research Funds for the Central Universities, Special Funds for the Cultivation of Guangdong College Students' Scientific and Technological Innovation [pdjha0005]. We thank Dr Hulin Tai (SYSU) for assistance with 2D NMR and Prof. Duxia Cao (University of Jinan), Dr Xi-Juan Chao (SYSU), Dr Yu Guo (SYSU) and Teng-Fang Long (SYSU) for their guidance and assistance with the fluorescence experiments.

\section{Notes and references}

1 G. G. Gundersen and H. J. Worman, Nuclear positioning, Cell, 2013, 152, 1376-1389.

2 Z. Dou, et al., Cytoplasmic chromatin triggers inflammation in senescence and cancer, Nature, 2017, 550, 402-406.

3 F. Gasset-Rosa, et al., Polyglutamine-expanded huntingtin exacerbates age-related disruption of nuclear integrity and nucleocytoplasmic transport, Neuron, 2017, 94, 48-57.

4 Q. Zhou, et al., Loss-of-function mutations in TNFAIP3 leading to A20 haploinsufficiency cause an early-onset autoinflammatory disease, Nat. Genet., 2016, 48, 67-73.

5 N. Tanaka, T. Aoyama, S. Kimura and F. J. Gonzalez, Targeting nuclear receptors for the treatment of fatty liver disease, Pharmacol. Ther., 2017, 179, 142-157.

6 S. Loft and H. E. Poulsen, Cancer risk and oxidative DNA damage in man, J. Mol. Med., 1996, 74, 297-312.
7 J. A. Imlay, Cellular defenses against superoxide and hydrogen peroxide, Annu. Rev. Biochem., 2008, 77, 755-776.

$8 \mathrm{~S}$. Nemmiche, Oxidative signaling response to cadmium exposure, Toxicol. Sci., 2017, 156, 4-10.

9 P. Chabosseau, J. Woodier, R. Cheung and G. A. Rutter, Sensors for measuring subcellular zinc pools, Metallomics, 2018, 10, 229-239.

10 G. Simic, et al., Monoaminergic neuropathology in Alzheimer's disease, Prog. Neurobiol., 2017, 151, 101-138.

11 Z. Meng and L. Zhang, Cytogenetic damage induced in human lymphocytes by sodium bisulfite, Mutat. Res., 1992, 298, 63-69.

$12 \mathrm{~N}$. Sang, et al., $\mathrm{SO}_{2}$ inhalation contributes to the development and progression of ischemic stroke in the brain, Toxicol. Sci., 2010, 114, 226-236.

13 G. Qin, J. Wang and N. Sang, Sulfur dioxide inhibits expression of mitochondrial oxidative phosphorylation genes encoded by both nuclear DNA and mitochondrial DNA in rat lungs, Environ. Sci. Pollut. Res., 2016, 24, 25272534.

14 D. W. Domaille, E. L. Que and C. J. Chang, Synthetic fluorescent sensors for studying the cell biology of metals, Nat. Chem. Biol., 2008, 4, 168-175.

15 T. Ueno and T. Nagano, Fluorescent probes for sensing and imaging, Nat. Methods, 2011, 8, 642-645.

16 D. Wu, et al., Fluorescent chemosensors: the past, present and future, Chem. Soc. Rev., 2017, 46, 7105-7123.

17 K. Kikuchi, Design, Synthesis and biological application of chemical probes for bio-imaging, Chem. Soc. Rev., 2010, 39, 2048-2053.

$18 \mathrm{~K} . \mathrm{Gu}$, et al., Real-time tracking and in vivo visualization of beta-galactosidase activity in colorectal tumor with a ratiometric near-infrared fluorescent probe, J. Am. Chem. Soc., 2016, 138, 5334-5340.

19 M. H. Lee, J. S. Kim and J. L. Sessler, Small molecule-based ratiometric fluorescence probes for cations, anions, and biomolecules, Chem. Soc. Rev., 2015, 44, 4185-4191.

20 L. He, B. Dong, Y. Liu and W. Lin, Fluorescent chemosensors manipulated by dual/triple interplaying sensing mechanisms, Chem. Soc. Rev., 2016, 45, 6449-6461.

21 F. Qian, et al., Visible light excitable $\mathrm{Zn}^{2+}$ fluorescent sensor derived from an intramolecular charge transfer fluorophore and its in vitro and in vivo application, J. Am. Chem. Soc., 2009, 131, 1460-1468.

22 D. Srikun, E. W. Miller, D. W. Domaille and C. J. Chang, An ICT-based approach to ratiometric fluorescence imaging of hydrogen peroxide produced in living cells, J. Am. Chem. Soc., 2008, 130, 4596-4597.

23 Y. Chen, et al., A ratiometric fluorescent probe for rapid detection of hydrogen sulfide in mitochondria, Angew. Chem., Int. Ed., 2013, 52, 1688-1691.

$24 \mathrm{H}$. Takakusa, et al., Design and synthesis of an enzymecleavable sensor molecule for phosphodiesterase activity based on fluorescence resonance energy transfer, J. Am. Chem. Soc., 2002, 124, 1653-1657.

25 M. M. Henary, Y. Wu and C. J. Fahrni, Zinc(II)-selective ratiometric fluorescent sensors based on inhibition of 
excited-state intramolecular proton transfer, Chem.-Eur. J., 2004, 10, 3015-3025.

26 V. S. Padalkar and S. Seki, Excited-state intramolecular proton-transfer (ESIPT)-inspired solid state emitters, Chem. Soc. Rev., 2016, 45, 169-202.

27 W. Lin, L. Yuan, Z. Cao, Y. Feng and J. Song, Through-bond energy transfer cassettes with minimal spectral overlap between the donor emission and acceptor absorption: coumarin-rhodamine dyads with large pseudo-Stokes shifts and emission shifts, Angew. Chem., Int. Ed., 2010, 49, 375379.

28 L. Zhou, et al., Molecular engineering of a TBET-based twophoton fluorescent probe for ratiometric imaging of living cells and tissues, J. Am. Chem. Soc., 2014, 136, 9838-9841.

29 J. A. Sclafani, M. T. Maranto, T. M. Sisk and S. A. Van Arman, An aqueous ratiometric fluorescence probe for $\mathrm{Zn}$ (II), Tetrahedron Lett., 1996, 37, 2193-2196.

$30 \mathrm{Z}$. Xu, et al., Unique sandwich stacking of pyrene-adeninepyrene for selective and ratiometric fluorescent sensing of ATP at physiological pH, J. Am. Chem. Soc., 2009, 131, 15528-15533.

$31 \mathrm{~J}$. B. Grimm, et al., A general method to improve fluorophores for live-cell and single-molecule microscopy, Nat. Methods, 2015, 12, 244-250.

32 Z. Yang, et al., Macro-/micro-environment-sensitive chemosensing and biological imaging, Chem. Soc. Rev., 2014, 43, 4563-4601.

$33 \mathrm{Y}$. Wen, et al., A highly sensitive ratiometric fluorescent probe for the detection of cytoplasmic and nuclear hydrogen peroxide, Anal. Chem., 2014, 86, 9970-9976.

34 B. C. Dickinson, Y. Tang, Z. Chang and C. J. Chang, A nuclear-localized fluorescent hydrogen peroxide probe for monitoring sirtuin-mediated oxidative stress responses In Vivo, Chem. Biol., 2011, 18, 943-948.

35 D. Srikun, A. E. Albers, C. I. Nam, A. T. Iavarone and C. J. Chang, Organelle-targetable fluorescent probes for imaging hydrogen peroxide in living cells via SNAP-tag protein labeling, J. Am. Chem. Soc., 2010, 132, 4455-4465.

36 L. Zeng, et al., A novel and photostable pH probe for selectively staining nuclei in living cells, Analyst, 2013, 138, 7083.

37 A. Nakamura and S. Tsukiji, Ratiometric fluorescence imaging of nuclear $\mathrm{pH}$ in living cells using Hoechst-tagged fluorescein, Bioorg. Med. Chem. Lett., 2017, 27, 3127-3130.

38 B. Diaz de Grenu, et al., Chemical speciation of $\mathrm{MeHg}(+)$ and $\mathrm{Hg}(2+)$ in aqueous solution and HEK cells nuclei by means of DNA interacting fluorogenic probes, Chem. Sci., 2015, 6, 3757-3764.

39 H. Zhu, J. Fan, J. Du and X. Peng, Fluorescent Probes for Sensing and Imaging Within Specific Cellular Organelles, Acc. Chem. Res., 2016, 49, 2115-2126.

$40 \mathrm{~T}$. Morisaki, et al., Real-time quantification of single RNA translation dynamics in living cells, Science, 2016, 352, 1425-1429.

41 Y. V. Suseela, N. Narayanaswamy, S. Pratihar and T. Govindaraju, Far-red fluorescent probes for canonical and non-canonical nucleic acid structures: current progress and future implications, Chem. Soc. Rev., 2018, 47, 1098-1131.

42 Y. Liu, J. Niu, W. Wang, Y. Ma and W. Lin, Simultaneous imaging of ribonucleic acid and hydrogen sulfide in living systems with distinct fluorescence signals using a single fluorescent probe, Adv. Sci., 2018, 5, 1700966.

43 G. Lukinavicius, et al., SiR-Hoechst is a far-red DNA stain for live-cell nanoscopy, Nat. Commun., 2015, 6, 8497.

$44 \mathrm{D}$. Li, et al., Nucleic acid-selective light-up fluorescent biosensors for ratiometric two-photon imaging of the viscosity of live cells and tissues, Chem. Sci., 2016, 7, 22572263.

45 B. Dumat, et al., DNA switches on the two-photon efficiency of an ultrabright triphenylamine fluorescent probe specific of AT regions, J. Am. Chem. Soc., 2013, 135, 12697-12706.

46 J. L. Kolanowski, F. Liu and E. J. New, Fluorescent probes for the simultaneous detection of multiple analytes in biology, Chem. Soc. Rev., 2018, 47, 195-208.

47 Z. Meng and L. Zhang, Cytogenetic damage induced in human lymphocytes by sodium bisulfite, Mutat. Res. Genet. Toxicol., 1992, 298, 63-69.

48 G. Qin, J. Wang and N. Sang, Sulfur dioxide inhibits expression of mitochondrial oxidative phosphorylation genes encoded by both nuclear DNA and mitochondrial DNA in rat lungs, Environ. Sci. Pollut. Res., 2017, 24, 25272534 .

49 T. Finkel and N. J. Holbrook, Oxidants, oxidative stress and the biology of ageing, Nature, 2000, 408, 239-247.

50 N. Sang, Y. Yun, H. Li, L. Hou, M. Han and G. Li, $\mathrm{SO}_{2}$ inhalation contributes to the development and progression of ischemic stroke in the brain, Toxicol. Sci., 2010, 114, 226-236.

51 Z. Meng, G. Qin, B. Zhang and J. Bai, DNA damaging effects of sulfur dioxide derivatives in cells from various organs of mice, Mutagenesis, 2004, 19, 465-468.

52 Y. Yue, et al., Dual-Site Fluorescent Probe for Visualizing the Metabolism of Cys in Living Cells, J. Am. Chem. Soc., 2017, 139, 3181-3185.

53 V. S. Lin, W. Chen, M. Xian and C. J. Chang, Chemical probes for molecular imaging and detection of hydrogen sulfide and reactive sulfur species in biological systems, Chem. Soc. Rev., 2015, 44, 4596-4618.

54 Y. Liu, et al., A mitochondria-targeted colorimetric and ratiometric fluorescent probe for biological $\mathrm{SO}_{2}$ derivatives in living cells, Chem. Commun., 2015, 51, 10236-10239.

55 Y. Yang, Q. Zhao, W. Feng and F. Li, Luminescent chemodosimeters for bioimaging, Chem. Rev., 2013, 113, 192-270.

56 L. Tang, et al., A mitochondria-targetable fluorescent probe for ratiometric detection of $\mathrm{SO}_{2}$ derivatives and its application in live cell imaging, Sens. Actuators, B, 2017, 247, 421-427.

57 Y. Zhang, et al., Reversible Fluorescent Probe for Selective Detection and Cell Imaging of Oxidative Stress Indicator Bisulfite, Anal. Chem., 2016, 88, 4426-4431.

$58 \mathrm{~W}$. $\mathrm{Xu}$, et al., A mitochondria-targeted ratiometric fluorescent probe to monitor endogenously generated 
sulfur dioxide derivatives in living cells, Biomaterials, 2015, 56, 1-9.

$59 \mathrm{~J} . \mathrm{Xu}$, et al., A mitochondria-targeted ratiometric fluorescent probe for rapid, sensitive and specific detection of biological $\mathrm{SO}_{2}$ derivatives in living cells, Biosens. Bioelectron., 2016, 77, 725-732.

60 Y. Xue, et al., Human telomeric DNA forms parallel-stranded intramolecular G-quadruplex in $\mathrm{K}^{+}$solution under molecular crowding condition, J. Am. Chem. Soc., 2007, 129, 1118511191.

$61 \mathrm{H}$. Mitsuhashi, et al., Oxidative stress-dependent conversion of hydrogen sulfide to sulfite by activated neutrophils, Shock, 2005, 24, 529-534.
62 M. H. Stipanuk, J. De la Rosa and L. L. Hirschberger, Catabolism of cyst(e)ine by rat renal cortical tubules, $J$. Nutr., 1990, 120, 450-458.

63 G. Li, et al., A dinuclear iridium(III) complex as a visual specific phosphorescent probe for endogenous sulphite and bisulphite in living cells, Chem. Sci., 2013, 4, 4426.

64 D. P. Li, Z. Y. Wang, H. Su, J. Y. Miao and B. X. Zhao, Fluorescence detection of endogenous bisulfite in liver cancer cells using an effective ESIPT enhanced FRET platform, Chem. Commun., 2017, 53, 577-580. 